\title{
Trabalhador de enxada em roça alheia: o léxico dos estados da Bahia e de Sergipe na década de \\ 1960
}

\section{The hoe worker in farm of others: the lexicon of states of Bahia and Sergipe in the 1960s}

\author{
Jadione Cordeiro de Almeida ${ }^{1}$ \\ https://orcid.org/0000-0002-7363-7198 \\ Marcela Moura Torres Paim² \\ http://orcid.org/0000-0002-1303-3763 \\ Josane Moreira de Oliveira \\ https://orcid.org/0000-0002-9661-1804
}

\begin{abstract}
Resumo: À luz da Dialetologia e de seu principal método, a geolinguística, este artigo traz uma releitura das cartas trabalhador de enxada em roça alheia que compõem o Atlas Prévio dos Falares Baianos e o Atlas Linguístico de Sergipe, com vistas a delimitar as áreas que circunscrevem as realizações das variantes léxicas para o tema em questão nos estados da Bahia e de Sergipe na década de 1960. Por se tratar de um trabalho de base lexicológica, levou-se em consideração a consulta de três renomados dicionários de língua portuguesa. Rossi (1963), embora limitado sua análise ao perímetro baiano, foi basilar para a reflexão sobre essas lexias dentro do território
\end{abstract}

${ }^{1}$ PPGLinC/Universidade Federal da Bahia. E-mail: jadionealmeida@gmail.com 2 PPGLinC/Universidade Federal da Bahia. E-mail: marcelamtpaim@yahoo.com.br

3 PPGEL/Universidade Estadual de Feira de Santana; PPGLinC/Universidade Federal da Bahia. E-mail: josanemoreira@hotmail.com 
dos falares baiano. Este artigo já sinaliza macaqueiro e pataqueiro como as principais representantes nesse território linguístico.

Palavras-chave: Trabalhador de enxada; Falares baianos; Macaqueiro; Pataqueiro; Ganhador.

\begin{abstract}
According to the Dialecology and its main method, the geolinguistics, this article brings a rereading of the hoe worker in farm of of others's linguistic maps of the Atlas Prévio dos Falares Baianos and the Linguistic Atlas of Sergipe, with a view to delimiting the areas that circumscribe the realizations of the lexical variants for the subject in question in the states of Bahia and Sergipe in the 1960s. Because it was a lexicological work, it was considered the consultation of three renowned Portuguese-language dictionaries. Rossi (1963), although limited his analysis to the Bahian perimeter, was basilar for the reflection on these lexemes within the territory of the Bahian dialects. This article already signals macaqueiro and pataqueiro as the main representatives in this linguistic area.
\end{abstract}

Keywords: Hoe worker; Bahian Dialects; Macaqueiro; Pataqueiro; Ganhador.

\title{
Introdução
}

A geolinguística não é o único método da Dialetologia, mas, sem sobra de dúvidas, é o método mais usado há quase dois séculos pelos dialetólogos (CARDOSO, 2010). Também é considerado o método mais sistemático para a escolha das localidades, da formação da rede de pontos e dos informantes. Para a elaboração dos questionários, faz-se uso de critérios rigorosos. Ademais cada pergunta formulada deve levar em consideração a natureza contextual da Dialetologia, ou seja, nenhum fenômeno fonético, prosódico, morfossintático ou lexical tem motivo de ser investigado senão em oposição/contraste a uma ou muitas variantes, mesmo que, segundo Rossi (1967), essa distinção seja marcada pela ausência de elemento linguístico correspondente.

É importante salientar que os estudos dialetológicos se firmam no tripé rede de pontos, informante e questionário (CARDOSO, 2010). Sobre a escolha de determinada área, observamse características espaciais, históricas, econômicas, sociais, culturais, demográficas, linguísticas, entre outras.

A malha da rede de pontos traçada pelo método geolinguístico pode cobrir áreas conforme a natureza do atlas e/ou do estudo a ser desenvolvido: local, regional, nacional, continental ou de famílias de línguas. Para a escolha do informante, faz-se necessário observar questões como: "número ideal a ser inquerido; a identificação - naturalidade, vinculação familiar; inserção social; características sociais - a idade, o gênero/sexo, a escolaridade" 
(CARDOSO, 2010, p. 91). Aspectos físicos também devem ser levados em consideração, entre outros se o falante apresenta algum problema fonoarticulatório na integridade do aparelho fonador e o tipo de reflexo que acarreta na sua elocução, conforme destaca Cardoso (2010). Vale ressaltar que, com o crescente interesse pela Dialetologia vertical, caiu o interesse pelo perfil de informante HARAS - homem, adulto, rurícola, analfabeto e sedentário, como traduziu Zágari (1998 apud MOTA; CARDOSO, 2006) o conceito de Chambers e Trudgill (1994): NORM (nonmobile, older, rural, male).

Quanto à natureza, à elaboração e à aplicação do questionário, o pesquisador deve levar em consideração a natureza do fenômeno a ser estudado e a cultura local em que o informante está inserido. Além do mais, esse conhecimento etnográfico orientará o pesquisador sobre a exequibilidade de questões onomasiológicas (quando se busca o conjunto de formas a partir do conceito, ou da utilização do método coisa-palavra) e/ou semasiológicas (quando se buscam diferentes conceitos para uma única forma). Para Cardoso (2010), deve-se dar importância especial também para o tipo de registro das informações, a preparação do inquiridor, a ficha de controle do informante, a catalogação e o arquivamento do material.

Essas e outras preocupações já eram consideradas parcial ou totalmente desde a elaboração do Atlas Prévio dos Falares Baianos (APFB) até a efetiva publicação dos volumes 1 e 2 do Atlas Linguístico do Brasil (ALiB). Nesse sentido, não se pode negar o comprometimento e o rigor acadêmico da Dialetologia para com o estudo da variação linguística também em terras brasileiras, sobretudo na Bahia.

Embora seguindo a tradição monodimensional, por controlar apenas a variação diatópica em suas cartas, o APFB foi o primeiro atlas sobre um estado brasileiro. Praticamente a mesma equipe, que foi coordenada pelo professor Rossi, também elaborou o Atlas Linguístico de Sergipe (ALS). Logo, aos cinquenta pontos que compuseram a malha do APFB, foram acrescentados mais quinze pontos para cobrir o Estado de Sergipe, uma vez que parte também deste Estado, segundo Nascentes (1953), possui características próprias do 'falar baiano'.

\section{Dialeto, variedade ou falar baiano?}

Chambers e Trudgill (1994) questionam três definições comuns para dialetos: i) língua não substandar, de pouco prestígio social; ii) língua que não tem tradição escrita, sobretudo aquelas faladas em comunidades isoladas e/ou de difícil acesso; iii) comportamento linguístico de algumas classes que foge à prescrição da norma padrão de uma língua. Ferreira e Cardoso 
(1994, p. 12) definem dialeto como um "subsistema inserido nesse sistema abstrato que é a própria língua".

Para este artigo, em especial, não se considera como dialeto ou variedade linguística a amostra coletada no Estado da Bahia e de Sergipe, embora este conceito seja adequado e/ou prudente, segundo Chambers e Trudgill (1994). Prefere-se a noção de 'falar baiano', como adotou Rossi no título do APFB (ROSSI, 1965). Em linha conceitual semelhante, Nascentes (1953) trata a fala carioca como uma variedade do 'subfalar fluminense' e o português brasileiro (PB) como 'falar', talvez porque ainda na década de 1920 a noção de dialeto estivesse associada a um conceito estigmatizado em relação a uma língua oficial. Portanto este autor considerou mais prudente usar denominações como 'falares' e 'subfalares' para caracterizar, respectivamente, o PB e a variedade linguística baiana.

Seguindo a orientação de Nascentes (1953), o falar brasileiro compreende dois grandes grupos de falares: do Norte e do Sul, sendo o subfalar baiano, como ele o nomeia, parte intermediária entres esses dois falares. Assim, o subfalar baiano abrange os estados de Sergipe, Baía, Minas (Norte, Nordeste e Noroeste), Goiás (parte que vem da nascente do Paraíba, seguindo pelas serras dos Javais, dos Xavantes, do Fanha e do Pilar até a cidade de Pilar, Rio das Almas, Pirenópolis, Santa Luzia e Arrependidos) (NASCENTES, 1953, p. 26). 


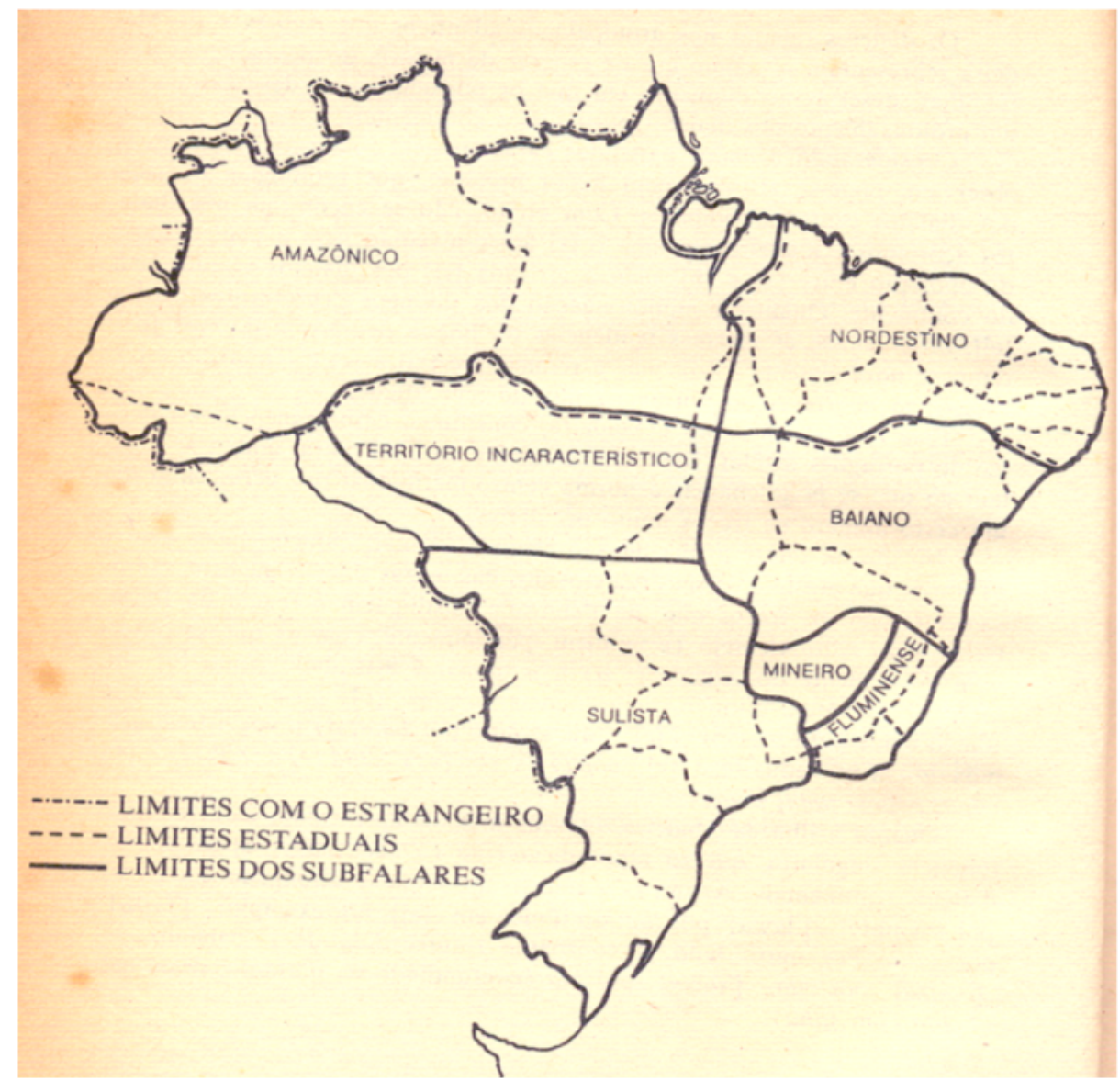

Figura 1: Divisão dialetal do Brasil (NASCENTES, 1953)

Fonte: Nascentes (1953, p. 18)

Desses quatro estados que compõem o falar baiano, Goiás não tem atlas até o momento e Minas Gerais, embora tenha publicado o Esboço de um Atlas Linguístico de Minas Gerais na década de 1970 (PASSINI; GAIO, 1977), entre suas cartas, não há nenhuma que contemple a questão envolvendo as designações para "trabalhador de enxada em roça alheia", diferentemente do APFB e do ALS ${ }^{4}$. A comissão do ALiB levantou esse dado, mas até o momento essa carta não foi publicada (CARDOSO et al., 2014). Por essas limitações metodológicas, seja pela ausência de atlas de Goiás ou de carta equivalente em Minas Gerais, neste trabalho, será considerada a amostra apenas das capitais e do interior dos estados da Bahia e de Sergipe na

4 Vale salientar que entre 1723 e 1823 as terras de Sergipe pertenciam à Bahia. E Sergipe mantinha fortes relações, sobretudo econômicas, com a Bahia por conta dessa subordinação política (AZEVEDO, 2009). 
década de 1960.

O APFB foi elaborado de janeiro de 1960 a novembro de 1962, tendo sido publicado em 1963 (ROSSI, 1963). A coleta dos dados do ALS ocorreu em seguida, na mesma década. Apenas no final da década de 1980, foi publicado o primeiro volume do ALS (FERREIRA; FREITAS; MOTA et al., 1987). Posto dessa forma, pode-se dizer que as transcrições fonéticas durante a aplicação do questionário pelos inquiridores do APFB e as gravações do ALS compõem juntas uma amostra significativa de uma mesma sincronia dos falares baianos, doravante FB.

\section{Designações para 'trabalhador de enxada' nos estados da Bahia e de Sergipe}

Segundo Rossi (1963), desprezando as variantes de realização da carta 23 do APFB, a lista completa das respostas dos informantes é composta por doze lexias: macaqueiro (21 pontos $^{5}$, mas consideraram-se 22 pontos neste trabalho), lavrador (13 pontos), pataqueiro (10 pontos) ${ }^{6}$, base jornal (6 pontos), roceiro (4 pontos), diarista ( 3 pontos), cavouqueiro (2 pontos), operário (2 pontos), pinhão [peão] (2 pontos), alugado (1 ponto), enxadeiro (1 ponto), rendeiro (1 ponto). Nessa lista, Rossi não cita, no entanto, a lexia ganhador, presente em 5 pontos do APFB.

Colhendo informações no texto e no respectivo mapa do apêndice de Rossi (1963) e verificando cada ponto do APFB, chegou-se a uma nova distribuição das lexias no mapa da Bahia. A releitura desse mapa e/ou dessas cartas buscou identificar a ocorrência de todas as lexias possíveis e não apenas as principais. No entanto, neste trabalho, algumas delas foram agrupadas na legenda outras (base jornal, roceiro, cavouqueiro, operário, pinhão [peão], enxadeiro e rendeiro). Elas foram assim agrupadas por alguns motivos, em especial:

a) as respostas não nomeariam especificamente 'trabalhador de enxada em roça

\footnotetext{
${ }^{5}$ Embora Rossi apresente 22 pontos, conforme indica a releitura da carta 23 (ver Carta 1), como locais da realização de macaqueiro, nesse próprio texto, o autor diz que foi anotada a lexia macaco nos pontos "14 e 35 mas não incluímos na carta" (1963, p. 5), no entanto isso não ocorreu, pois, além de sinalizar o ponto 14 com a realização de macaqueiro no apêndice, logo depois publicou-se o APFB com duas cartas para "trabalhador de enxada" cujo conteúdo de ambas sinaliza também o ponto 14 como local da realização de macaqueiro. Pelo exposto, resolveu-se seguir a orientação do APFB, contabilizando, portanto, vinte e duas ocorrências de macaqueiro na Bahia.

${ }^{6}$ No mesmo texto (ROSSI, 1963), o autor diz inicialmente serem 9 pontos, depois chega ao número de 10 pontos, como aparecem na carta 23 do APFB, mas conclui esquecendo-se de incluir o ponto 16 (provável erro de datilografia).
} 
alheia', como pinhão [peão] e operário;

b) as respostas não apresentam nenhuma relação aparente com essa função, como base jornal e rendeiro;

c) a lexia é derivada de uma palavra motivadora da pergunta do questionário ("efeito gatilho"), como, por exemplo, roceiro e enxadeiro, ou derivada da ação desse trabalhador, como cavouqueiro;

d) há poucas realizações nas respostas;

e) objetivou-se otimizar a leitura da carta e sua interpretação.

Embora as lexias lavrador e diarista, pelas justificativas apresentadas, devessem ser agrupadas também nessa categoria genérica, não o foram, pois apresentaram não só certo número de realizações, associadas à contiguidade das isoglossas, mas também por ocorrerem nos dois estados. Diferentemente do cartograma do apêndice de Rossi (1963), com apenas duas lexias (macaqueiro e pataqueiro), neste artigo, esse número foi ampliado. Vejam-se cartas a seguir: 


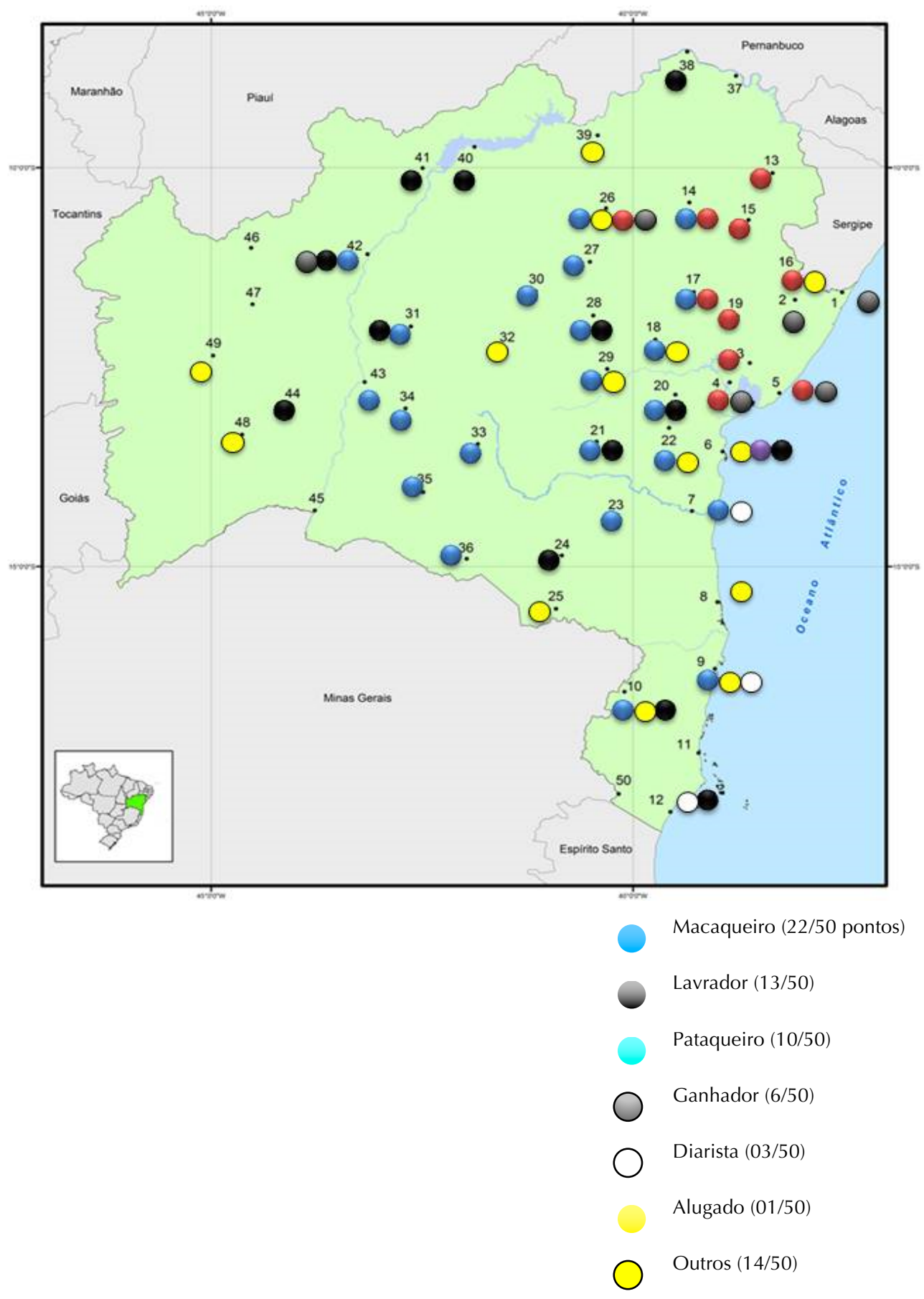




\section{BAHIA \\ APFB \\ Atlas Prévio dos Falares Baianos \\ REDE DE PONTOS}

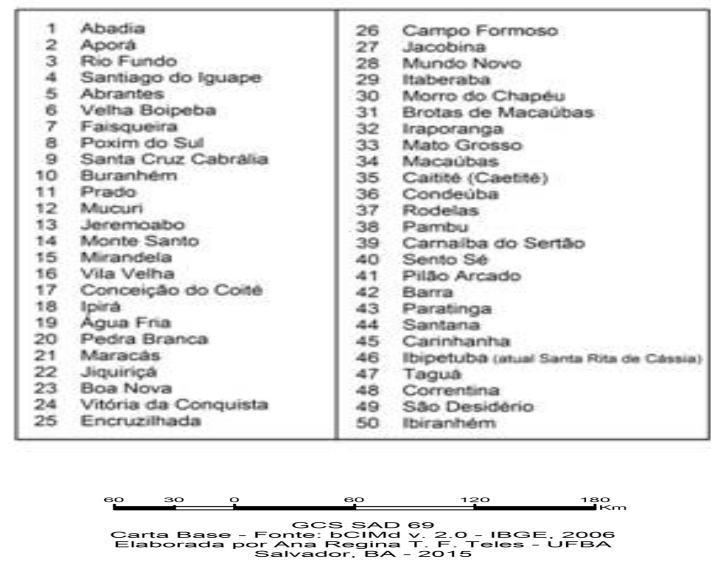

Carta 1: Designações para 'trabalhador de enxada em roça alheia' na Bahia 


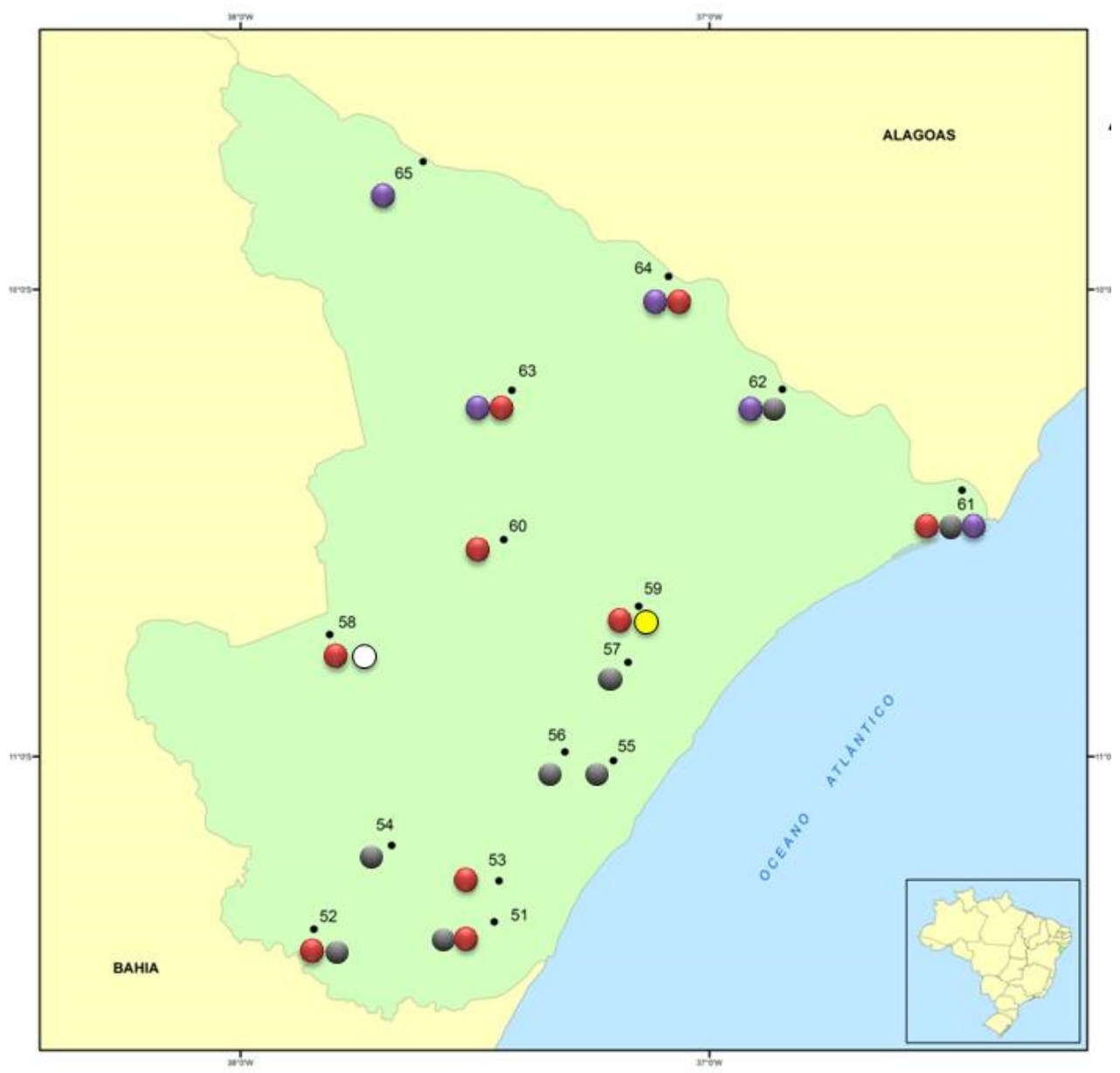

SERGIPE

APFB

Atlas Prévio dos Falares Baianos REDE DE PONTOS

\begin{tabular}{|l|l|}
\hline 51 & Santa Luzia do ltanhy \\
\hline 52 & Tomar do Geru \\
\hline 53 & Estânia \\
\hline 54 & Pedrinhas \\
\hline 55 & São Oristóvão \\
\hline 56 & Itaporanga diAjda \\
\hline 57 & Laranjeiras \\
\hline 58 & Simão Dias \\
\hline 59 & Divina Pastora \\
\hline 60 & Ribeirópolis \\
\hline 61 & Brejo Grande \\
\hline 62 & Propriá \\
\hline 63 & Nossa Senhora da Glória \\
\hline 64 & Gararu \\
\hline 65 & Gurralinho \\
\hline
\end{tabular}

Pataqueiro, ganhador da pataca (9/15 pontos)

Ganhador (08/15)

Trabalhador, - de aluguel, - de alugado, alugado (05/15)

Diarista $(01 / 15)$

$\bigcirc$ Outros $(01 / 15)$

$$
\begin{array}{lrrrr}
10 \quad 5 \quad 0 \quad 10 & 20 & 30 & & \\
\hline
\end{array}
$$

Base: base cartográfica integrada digital do Brasil ao milionésimo - bCIMd - IBGE, 2006 Tema: Banco de dados do Atlas Linguístico do Brasil Planejamento Cartográfico e Ediçăo da Base: Jamila Reis Gomes
Composição Temática: Flávio Ferreira Pimentel 


\section{Carta 2: Designações para 'trabalhador de enxada em roça alheia' em Sergipe}

Comparando as cartas, observa-se que, diferentemente de Sergipe (SE), na Bahia (BA), há pontos da malha em que os informantes não apresentaram denominações para 'trabalhador de enxada em roça alheia', a saber: pontos 37 (Sertão do São Francisco), 45 (Médio São Francisco), 46, 47 (Zona de Barreiras) e 50 (no extremo Sul). Quanto aos demais pontos, todos apresentam uma ou mais designações para a função. Ademais, a própria categoria outros pode apresentar mais de uma lexia realizadas num mesmo ponto. Essas ausências nesses pontos associadas ao contíguo uso genérico e/ou equivocado de lexias nos pontos 37, 38, 39, 40, 41, 44 e 48 (lavrador, roceiro, cavouqueiro) favorecem o traçado de uma isoglossa que acompanha e corta todo o Estado da Bahia a partir do caminho do rio São Francisco.

\section{Macaco e macaqueiro no sertão baiano}

Embora sejam raros os casos na literatura linguística em que acidentes geográficos são fatores influenciadores nas realizações linguísticas das pessoas, a posição do rio São Francisco foi imperativa para impedir que uma variante (macaqueiro) fosse conhecida e/ou usada depois de suas margens nas regiões Norte e Oeste do Estado (com exceção do ponto 42), logo - pela delimitação dos FB sugerida por Nascentes (1953), que inclui o Leste do Estado de Goiás ${ }^{7}$ - as lexias próprias desses falares que compõem o envelope sob o tema 'trabalhador de enxada em roça alheia', aparentemente, não se estendem ao perímetro desse Estado característico dos FB.

Em relação aos limites com Minas Gerais, porém, esse envelope dos FB parece coincidir com a proposta de Nascentes (1953), pois macaqueiro se estende até a divisa com o Norte desse Estado (perímetro característico dos FB) e, muito embora não seja possível a comparação com um atlas mineiro, pelo já justificado, Houaiss (2007) e Ferreira (1986), ao descreverem os verbetes macaqueiro e caipira, tomam-nos como sinônimos justamente no Estado de Minas Gerais: "5. Bras., S. da BA. Trabalhador rural da lavoura do cacau. 6. Bras., MG. V. caipira (1)..." (FERREIRA, 1986, p. 1057), mas não precisam a região de ocorrência de macaqueiro nesta concepção: “Caipira (...) 1. Habitante do campo ou da roça, particularmente

${ }^{7}$ Com os dados do ALiB, coletados até dia 18/09/2013, Isquerdo e Carvalho (2012) só encontraram, em toda a região Centro-Oeste do Brasil, capitais e interior, as lexias boia-fria, diarista, peão, peão diário, trabalhador e trabalhador braçal. Talvez seja imperativo o passar dessas décadas. 
os de pouca instrução e de convívio e modos rústicos e canhestros (...) Sin(ônimos) sendo alguns regionais (...) jeca, macaqueiro (...)" (FERREIRA, 1986, p. 314). Embora nem Ferreira (1986) nem Houaiss (2007) mencionem o labor com a enxada no verbete caipira, suas conceituações levam a crer que macaqueiro (sinônimo de caipira em Minas Gerais), se não é também sinônimo de trabalhador de enxada em roça alheia, surgiu deste conceito posto que ao trabalhador de enxada, normalmente, sempre são atribuídas essas características do caipira.

Também corroborando a proposta de Nascentes (1953) em direção ao Norte e ao Nordeste da Bahia, macaqueiro se estende antes da divisa com a malha dos falares nordestinos (FN) ao Norte do Estado e, coincidentemente, também apenas em direção ao Estado de Sergipe. Neste Estado, no entanto, a lexia pataqueiro faz uma intersecção entre os FB e os FN, pois ela ultrapassa os limites daqueles falares sugeridos pelo autor (NASCENTES, 1953, p. 18).

Em ordem do número de pontos onde ocorreram as realizações (ver Carta 1), macaqueiro ou, em dois pontos, macaco foram as variantes mais expressivas (22/50 pontos da Bahia, a saber: 7, 9, 10, 14, 17, 18, 20, 21, 22, 23, 26, 27, 28, 29, 30, 31, 33, 34, 35, 36, 42 e 43). Não ocorreram, porém, como resposta no Estado de Sergipe. Essas variantes cobrem uma isoglossa que começa a ser desenhada do extremo Sul, subindo pelo Sul, Sudoeste, parte do Leste, do Centro-Leste e do Oeste até chegar ao Centro-Norte, sendo identificadas também nos limites com a região Norte do estado baiano. Macaqueiro só não ocorre na região Nordeste da Bahia, onde predomina pataqueiro. Curiosamente, a área de realização de macaqueiro não é contígua ao Sudoeste e ao Sul, pois não foi localizada nos pontos 8, 24, 25, só ocorrendo novamente, com variantes concorrentes, nos pontos 9 e 10. Dentro dessas duas áreas, macaqueiro só concorre com as variantes genéricas (lavrador e diarista) e com aquelas do conjunto inexpressivo outros. Portanto macaqueiro foi a variante acolhida pelos baianos. Talvez tenha surgido antes, depois ou até ao mesmo tempo de sua concorrente típica mais expressiva dentro dos FB: pataqueiro. Sabe-se, no entanto, que na década de 1960 ambas concorriam não apenas em espaços distintos mas também em algumas localidades (pontos 14, 17, 26). Nestes três pontos, fica evidente a perda gradativa da força representativa de ambas as lexias, por conta desse "embate geográfico".

A lexia macaqueiro parece ser um brasileirismo, mais especificamente um regionalismo dos estados da Bahia e de Minas Gerais. No primeiro dicionário da língua portuguesa $^{8}$, Bluteau (1712-1728), por exemplo, não apresenta esse verbete. Apenas

\footnotetext{
${ }^{8}$ Seria importante a comparação com outros dicionários escritos por portugueses nos séculos XIX e XX para melhores esclarecimentos.
} 
"MACACO. He palavra de Angola \& do Congo... e(s)pecie de bugio..." (BLUTEAU, 1716, p. 229) 9 e "MACACO. Morte macaca. Vulgarmente fallando he morte de(s)graçada..." $(B L U T E A U, 1728, \text { p. } 2)^{10}$. Essa segunda acepção justificaria talvez o uso de macaco para designar o trabalhador de uma atividade que paulatinamente lhe tiraria o vigor e lhe acarretaria inúmeras doenças pela posição física em que se encontra nesse tipo de trabalho, com uma jornada diária desumana e com exposição direta ao Sol. Macaco é uma lexia que apareceu nos pontos 14 e 35. Para Rossi (1963, p. 5),

\begin{abstract}
... apesar disso, creio que o aparecimento, difusão e fixação de macaqueiro (evidentemente na acepção em causa) só indireta e analogicamente deve ligar-se a macaco, não constituindo um caso de derivação pura e simples, mas antes um caso de substituição de uma forma (pataqueiro) que perdera substância com o desaparecimento de sua base (pataca ou pataco) pelo que, dentro das possibilidades do sistema linguístico, mais se aproximava ou virtualmente podia se aproximar... (ROSSI, 1963, p. 5)
\end{abstract}

Para Ferreira (1986) e Houaiss (2007), o verbete macaco, entre outras acepções, designaria ajudante de vaqueiro na Bahia. Aquele ainda precisa como sendo realizada no sertão da Bahia. Na condição apenas de ajudante de vaqueiro, o macaco não trabalharia de enxada na fazenda onde exercia sua função? Não seriam macaco e macaqueiro sinônimos ${ }^{11}$ e/ou mesmo esta lexia derivada daquela? Nos pontos 14 e 35 os informantes deram macaco como resposta a 'trabalhador de enxada em roça alheia', justamente pontos opostos da isoglossa. Talvez pontos onde a mudança de macaco para macaqueiro não tenha ocorrido por estarem nos limites da isoglossa (ponto 14 e 35) ou ainda porque a oposição na variação ocorre com outra lexia (pataqueiro, no ponto 14), sendo, portanto, desnecessário substituir macaco por macaqueiro, posto que, neste ponto, pataqueiro já seria uma variante comum.

A respeito da variação e da substituição de pataqueiro por macaqueiro sugeridas por Rossi (1963), não se pode ser tão categórico, posto que, segundo Houaiss (2007), esta lexia surgiu no início do século XIX (entre 1817 e 1819) para nomear trabalhadores rurais dos cacauais na Bahia, enquanto aquela surgiu quase oitenta anos depois, no final desse século (1899) como "B N. E. pej(orativo). Apelido dado pelos cassacos das estradas de ferro aos

\footnotetext{
${ }^{9}$ Encontra-se no volume 5 da obra.

${ }^{10}$ Localiza-se no volume 10 do dicionário.

${ }^{11}$ Macaco é uma lexia muito produtiva, designa mais funções além de ajudante de vaqueiro, como policial e guarda civil.
} 
lavradores" (HOUAISS, 2007, p. 2147). Também a lexia pataqueiro só teria razão de existir como forma pejorativa, usada pelos $\operatorname{cassacos}^{12}$, se essa alcunha fosse atribuída aos trabalhadores de enxada num período em que a pataca (nome da moeda da qual surge pataqueiro) tivesse um valor monetário irrisório, mas isso só ocorreu na década de 1830, quando uma pataca - em 1834, ano da última cunhagem do sistema de patacas (MALDONADO, 2016; AMATO; NEVES; RUSSO, 2004) - passou a valer apenas um "sorvete na melhor confraria" ou nem exatos dois refrescos no mesmo tipo de estabelecimento (GALLAS; GALLAS, 2007, p. 358). Até 1826, uma pataca valia o equivalente a 63 ovos $^{13}$ (cerca de R\$40,00) $(2007$, p. 328). Depois da vinda da Família Real para o Brasil (1808), houve grande inflação no País e, consequentemente, desvalorização da pataca, surgindo até mesmo a cunhagem dos 960 réis (três patacas), tamanha a desvalorização dessa moeda.

Assim, não parece ser pataqueiro a variante léxica mais antiga para designar 'trabalhador de enxada em roça alheia' na Bahia se as entradas nos dicionários de ambas as lexias e os valores monetários da pataca entre 1695 a 1834 forem levados em consideração na análise dessa questão. Ademais, como salienta Paranhos da Silva (1879-1882), o Brasil teria dois tipos de língua portuguesa, uma moderna ao litoral e outra antiga no interior até o final do século XIX. Essa realidade não parece ser diferente, pelo menos, até metade do século XX. Valendo-se também dessa máxima, cabe observar que pataqueiro é a variante que menos seguiu em direção ao sertão baiano, ficando mais próxima do litoral, portanto poderia ser a variante inovadora, enquanto macaqueiro se estendeu a quase todo o interior do Estado, hipoteticamente região de pouca inovação da língua. Logo poderia macaqueiro ser a variante mais antiga no Estado da Bahia. Veja-se a Figura 2:

\footnotetext{
12 Diferentemente do trabalhador de enxada em roça alheia, os cassacos eram homens que trabalhavam nas frentes de trabalho do Governo, num ciganismo constante, pois eram mais bem remunerados e tinham trabalho constante. Talvez por essa razão, julgaram-se melhor que os ditos pataqueiros.

${ }^{13}$ Quando a primeira pataca foi cunhada no Brasil, em 1696, na Bahia, seu valor monetário correspondia a aproximadamente 426 ovos. Já em 1731, valia 1,5 litros de azeite ou cerca de 86 ovos (GALLA, 2007).
} 


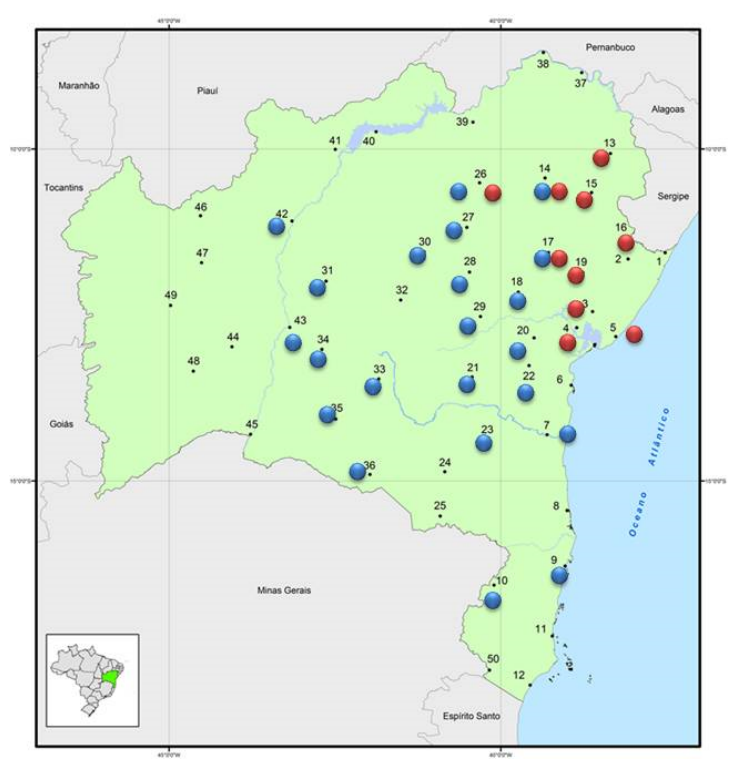

BAHIA

APFB

Atlas Prévio dos Falares Baianos REDE DE PONTOS
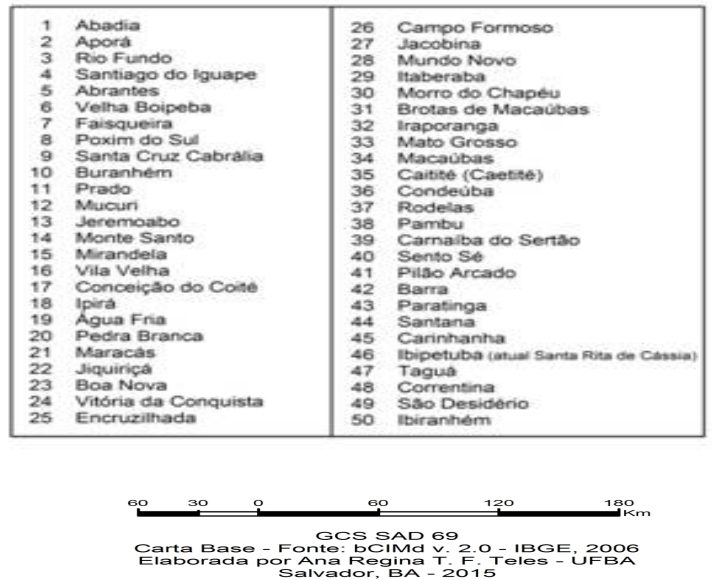

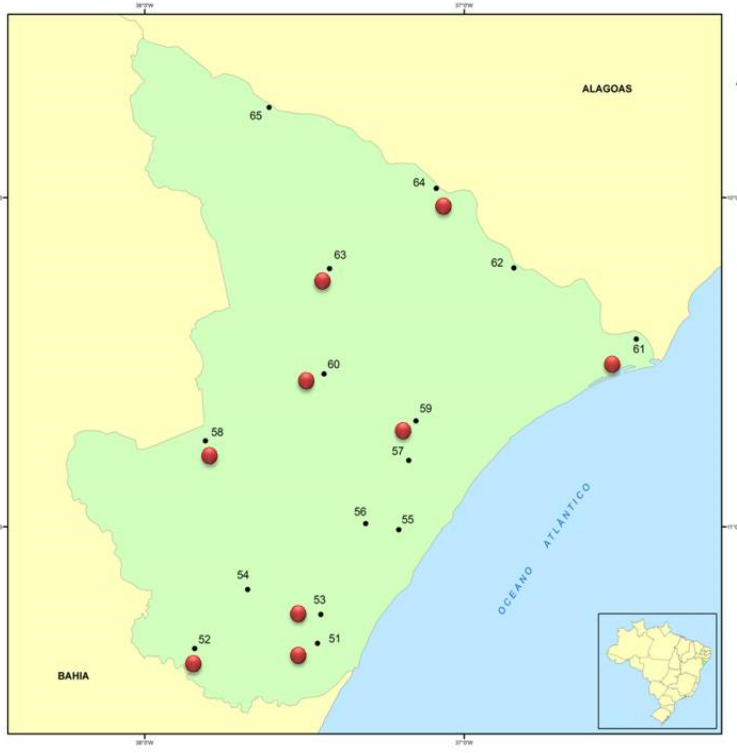

SERGIPE APFB

Atlas Prévio dos Falares Baianos REDE DE PONTOS

\begin{tabular}{|l|l|}
\hline 51 & Santa Luzia do Itanhy \\
\hline 52 & Tomar do Geru \\
\hline 53 & Estancia \\
\hline 54 & Pedrinhas \\
\hline 55 & Săo Cristóvăo \\
\hline 56 & Itaporanga d'Ajuda \\
\hline 57 & Laranjeiras \\
\hline 58 & Simáo Dias \\
\hline 59 & Divina Pastora \\
60 & Ribeirópolis \\
\hline 61 & Brejo Grande \\
62 & Propriá \\
\hline 63 & Nossa Senhora da Glória \\
64 & Gararu \\
65 & Curralinho \\
\hline
\end{tabular}

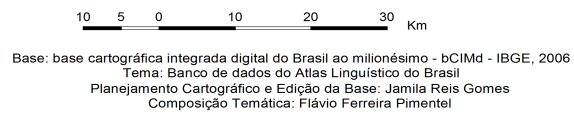

Macaqueiro (22/50 pontos)

Pataqueiro (10/50)

Figura 2: Principais designações para 'trabalhador de enxada em roça alheia' na Bahia e em Sergipe 
Para Rossi (1963, p. 5), no entanto, pataqueiro tem uma origem mais antiga pelo motivo oposto: "porque a área de pataqueiro é de uma zona de colonização mais antiga do que a de macaqueiro" ${ }^{14}$. Só um trabalho etimológico mais detalhado poderia desvendar essa questão envolvendo a origem e/ou datação dessas duas lexias.

Cabe observar que em quase todo o Estado baiano macaqueiro foi imperativa nas respostas para 'trabalhador de enxada em roça alheia' do APFB, mas expressões como "no macaco", "dar um dia no macaco" eram comuns no semiárido baiano e ainda o são, pelo menos como arcaísmo na fala descontraída dos HARAS mais idosos, para indicar que algum sertanejo estava trabalhando de enxada em roça alheia. Dessa forma, não é estranho, portanto, que a lexia macaqueiro advenha de macaco como sinônimo de trabalhador rural. Macaco e macaqueiro parecem ser usadas indiferentemente, sem se ter a impressão de falar-se de atividades distintas.

\section{Lavrador, diarista, trabalhador de aluguel e outros tantos}

Somados os 13 pontos onde ocorreu a lexia lavrador aos 3 pontos de diarista, aos 6 pontos de alugado e aos 15 pontos onde ocorreram outras lexias, tem-se o cômputo mais expressivo e extensivo das respostas. O envelope dessas quatro categorias ocorre em todo o território da Bahia, mas essas lexias aparecem aleatoriamente como alternativas de resposta ou, em alguns trechos, desaparecem no interior das isoglossas onde são imperativas as áreas de macaqueiro, na Bahia, e pataqueiro e ganhador, na Bahia e em Sergipe.

Esse envelope de respostas não específicas para o questionário poderia demonstrar desconhecimento do tema (respostas como as de base jornal, ou as de base aluguel, roceiro, operário, enxadeiro, rendeiro ou lavrador: este seria o dono ${ }^{15}$ ou não da terra cultivada, empregador ou empregado, rico ou pobre?) ou atestar o uso de eufemismos ou mesmo de generalização ${ }^{16}$ (extensão semântica) de lexias para abarcar mais uma função (como diarista,

\footnotetext{
${ }^{14}$ Cabe observar, como destaca o próprio Rossi (1963, p. 6) no final do artigo, que, para provar essa hipótese, "precisaria para ser confirmada ou rechaçada, de submeter a um exame histórico-cronológico que confesso não ter o mínimo de condição de realizar. Sobre a cronologia das formas (pataqueiro e macaqueiro) não disponho de qualquer informação nem da esperança de poder tão cedo obtê-la por mim".

${ }^{15}$ No século XVII, por exemplo, "lavrador de cana" era um distinto fornecedor de matéria-prima para os donos de engenhos, disputando com estes em nível de importância na sociedade brasileira daquela época (cf. BETHELL, 1999). Agricultor pode ser aquele que cultiva a própria terra.

${ }^{16} \mathrm{O}$ resultado de Isquerdo e Carvalho (2012), mesmo obtido cinquenta anos depois de lançado o APFB e sobre outra região, leva a crer que as lexias diarista, peão e trabalhador (alugado) são de uso genérico pela população brasileira.
} 
pinhão/peão, cavouqueiro ${ }^{17}$ ). Pela dimensão limitada de um artigo, apenas algumas dessas lexias são comentadas a seguir.

Seguindo a delimitação do PB de Paranhos da Silva (1879), sendo a região litorânea o perímetro onde se falaria o português moderno e/ou inovador no Brasil, é natural a lexia diarista ocorrer apenas nos pontos limítrofes com o mar (7, 9 e 12 na Bahia) e, ocasionalmente, em apenas um ponto do interior de Sergipe, não tão distante da região litorânea (ponto 58). Sobre essa lexia, Rossi (1963, p. 2) acredita que "pelo intenso uso geral e urbano me parece de introdução recente, além de pouco ou nada adstrito ao trabalho propriamente rural".

Nesse mesmo sentido, a categoria outros ${ }^{18}$, que é diversificada, ocorre como alternativa às respostas nos pontos mais próximos ao litoral. Com exceção dos pontos 48 e 49 , a categoria outros divide a Bahia ao meio, numa isoglossa de itens totalmente diversificados, sobretudo na direção do litoral.

Respostas com a base aluguel, com exceção da ocorrência entre as alternativas do ponto 6 na Bahia, só aparece na área de Sergipe cuja caracterização já é tida como FN, segundo Nascentes (1953). Assim, pelo traçado isoglóssico, alugado não seria uma lexia dos FB. Nas respostas do ALS, essa categoria reúne respostas diversificadas como trabalhador, - de aluguel, - de alugado, alugado. Na Bahia, aparece somente como alugado. Apenas no ponto de Sergipe mais distante de Bahia (ponto 65), esse conjunto de respostas com a base aluguel é categórico. Como sempre esse envelope de variantes com a base aluguel oscila como alternativa a outras lexias, não parece, portanto, uma lexia típica para nomear 'trabalhador de enxada em roça alheia'. Se assim o fosse, seria uma lexia dos FN.

Assim como macaco e macaqueiro, lavrador, embora generalizante, é uma lexia que só ocorre no Estado da Bahia. Apareceu como resposta em 13/50 pontos: 6, 10, 12, 20, 21, 24, 28, 31, 38, 40, 41, 42 e 44. Por ser uma variante genérica, não surge eventualmente apenas nas respostas da região Nordeste, onde pataqueiro é imperativa e parece não ser também naturalmente a resposta adequada ao questionário para os informantes do Centro-Norte e Sul do Estado, regiões margeadas pelas isoglossas onde macaqueiro é majoritária ou, às vezes, categórica nas respostas dos nativos. Assim como a categoria outros, e pelas mesmas razões,

17 "Cavouqueiro, ou cabouqueiro. O primeiro me parece melhor, porque vem de cavar. O que arranca pedra; o que corta, \& tira as pedras da pedreira" (BLUTEAU, 1712, p. 216). Por essa acepção, cavouqueiro não parece equivaler a 'trabalhador de enxada em roça alheia'.

${ }^{18}$ Embora esta categoria reúna várias respostas, o que implicaria o não uso da categoria de forma global, neste artigo, por limitação de espaço, optou-se por agrupar estas lexias sob um mesmo rótulo. Ademais, muitas dessas respostas mostravam-se distantes da denominação de 'trabalhador de enxada em roça alheia'. 
lavrador ocorre num perímetro mais próximo ao litoral. Coincidentemente, apareceu acompanhando toda a extensão do rio São Francisco, tanto na margem direita quanto na esquerda, do ponto 38 descendo até o 44, formando com a categoria outros uma área caracterizada praticamente por lexias imprecisas e/ou não típicas dos FB. Embora distante do litoral, toda essa faixa é cortada por uma via fluvial propícia a uma maior interação entre pessoas e, eventualmente, a um maior número de inovações e/ou perda de arcaísmos na fala dos nativos ${ }^{19}$.

\section{Ganhador de patacas}

Rossi (1963, p. 2), revisitando alguns dicionários, chega à conclusão de que o conceito de ganhador ocorre nessas obras como brasileirismo ou mesmo regionalismo de Pernambuco e Alagoas, "sempre no sentido de carregador, môço de frete, e que de fato deve explicar-se como sobrevivência da sociedade escravocrata, durante a qual escravos e libertos eram postos nesse serviço, é ainda corrente com o mesmo sentido em Salvador". Houaiss (2007), porém, amplia a cobertura de ganhador ${ }^{20}$, tratando esse verbete como um regionalismo do Nordeste do Brasil: “... diz-se de ou trabalhador que ganha por dia (...) ou aquele que conduz ou transporta carga; carregador..." (2007, p. 1426)

Embora ganhador seja vista como uma lexia distinta de pataqueiro por Rossi (1963), curiosamente o traçado da isoglossa que comporta a área de pataqueiro é acompanhado por aquele que comporta a área de ganhador (são 6 pontos na Bahia: 1, 2, 4, 5, 26 e 42; e 8 pontos em Sergipe: 51, 52, 54, 55, 56, 57, 61 e 62). Com exceção dos pontos 26 e 42 na Bahia, esta lexia acompanha aquela num perímetro mais próximo do litoral. No ponto 26 (BA), pataqueiro surge como a explicação de "ganhador, que ganha meia pataca" (ROSSI, 1963, p. 4) e no ponto 61 (SE), pataqueiro é registrado no ALS como "ganhador da pataca". Essas evidências nos pontos 26 e 61, somadas à contiguidade das áreas de pataqueiro e de ganhador, sugerem uma possível proximidade semântica entre essas lexias: talvez esta seria uma extensão daquela, a ponto de ganhador (de pataca) nomear outras categorias de trabalhadores, de forma genérica, não só

\footnotetext{
${ }^{19}$ Numa de suas aulas, a professora Suzana Cardoso, sinalizou que algo semelhante ocorria com o $r$ retroflexo, posto que esse fenômeno acompanharia toda essa extensão do rio São Francisco.

${ }^{20}$ Entrada em 1622, mas Houaiss (2007) não revela em que acepção. Ver Tempo de agora, de Martim Afonso de Miranda.
} 
trabalhador de enxada. Ademais, em vários pontos dessas duas áreas, e apenas nelas, pataqueiro e ganhador (de pataca) são variantes nos mesmos pontos: 4, 5, 26 (BA) e 51, 52 e 61 (SE). Entre elas há proximidade geográfica bem como possível relação semântica. Se hipoteticamente tidas como sinônimas, ambas formariam uma rede contígua e mais densa, com ocorrências em 27 pontos ocupando os dois Estados, superando em número de pontos todas as demais lexias.

Se ganhador for vista, no entanto, como uma lexia independente de pataqueiro, esta, em comparação com as demais lexias dos FB, ocorre em 10 pontos da Bahia $(3,4$, 5, 13, 14, $15,16,17,19$ e 26) e em 9 de Sergipe (51, 52, 53, 58, 59, 60, 61, 63 e 64), cobrindo uma malha de 19 pontos contíguos que toma parte do Centro-Leste, do Norte, do Leste e do Nordeste da Bahia, estendendo-se praticamente por todo o Estado de Sergipe. Entre as explicações para a forma pataqueiro, Rossi (1963, p. 3) usa como ilustração as seguintes falas dos informantes para explicar essa lexia: "ser o que trabalha na roça dos outros, para ganhar dinheiro" (ponto 17), "no tempo das patacas" (ponto 26), "pessoa que ganha fazendo trabalhinho" (ponto 3), "os homens que vinham do sertão diziam assim, que eram pataqueiro" (ponto 4), "é o que não tem roça, ganha patacas, é diarista" (ponto 5). Algumas dessas explicações confirmam empiricamente a origem da lexia pataca (pontos 5 e 26) e revelam ser uma designação secular (ponto 26).

Couto (1904 apud MARROQUIM, 1996, p. 97), ao descrever um engenho no ciclo da cana-de-açúcar em Pernambuco, diz que "o mestre de Açúcar ganha(va) todos os dias 640 rs. (duas patacas) e o Banqueiro 320 rs. (uma pataca)". Essas são funções distintas num engenho daquele período. Ademais, até o início do século XIX, uma pataca gozava de prestígio monetário, mas depois, já em 1834, era irrisório esse valor, podendo perfeitamente ser o valor pago por uma mão de obra pouco valorizada, como a de um trabalhador de enxada, num período em que o trabalho servil (de escravos) ainda era legitimado e maciço. Se surgiu, de fato, no fim do século XIX, como alcunha dada pelos cassacos das estradas de ferro aos lavradores (HOUAISS, 2007), é natural que fosse um apelido pejorativo, posto ser atribuído a indivíduos recém-libertos ou mesmo cidadãos livres que, além de serem discriminados, concorriam com os imigrantes que chegaram ao País nesse período. Para o fazendeiro e também para os trabalhadores das ferrovias, o pataqueiro seria mais seria um faminto que aceitaria qualquer moeda para matar sua fome e a dos seus.

Assim como o descrito com o uso de lexias inovadoras e/ou generalizantes acompanhando toda a extensão do rio São Francisco, com a lexia pataqueiro ocorreu o mesmo, posto que essa lexia acompanha uma também relevante via de transporte: a ferrovia FCA. Pataqueiro, coincidentemente, ocorre em todo o perímetro à margem direita e à esquerda onde 
foi construída a primeira via férrea na BA (FCA) durante a segunda metade do século XIX, ligando Salvador ao São Francisco, bem como segue os trilhos em direção ao estado de Sergipe. Essa malha de pontos por onde se estende pataqueiro corrobora, portanto, a etimologia (nomeador: cassacos e nomeados: "trabalhadores de eitos nos engenhos de açúcar" ${ }^{21}$ ), pois essa área corresponde a uma região onde se aglomeraram em maior número engenhos nos dois Estados, e a entrada desse verbete apresentada por Houaiss (2007). Citando as linhas férreas em Alagoas e Pernambuco (iniciadas em 1858) bem como a FCA da Bahia (começada em 1881), Marroquim (1996) adverte que essas vias ajudaram a tirar do isolamento, inclusive linguístico, o matuto nordestino, apresentando-lhe, portanto, palavras além das suas, arcaicas. Pataqueiro seria, dessa forma, mais um regionalismo vindo nos vagões do progresso.

\section{Em poucas palavras}

A partir da análise dos atlas brasileiros disponíveis com dados da década de 1960 relacionados à variação lexical diatópica para designar 'trabalhador de enxada em roça alheia' dentro dos FB e da pioneira descrição e interpretação desse fenômeno em solo baiano feita por Rossi (1963), pode-se, com uma (re)análise do APFB e do ALS, chegar pontualmente às seguintes conclusões, por ora ainda parciais:

i) macaqueiro/macaco não só é a estratégia léxica majoritária e mais antiga, ocorrendo aparentemente apenas na Bahia e no Norte de Minas Gerais, sendo, portanto, legítima lexia dos FB, como também ultrapassa expressivamente os limites do perímetro cacaueiro apontados por Houaiss (2007) e Ferreira (1986);

ii) pela desvalorização da moeda 'pataca' tardiamente no sistema monetário brasileiro, pela localização à margem da primeira via férrea da Bahia e de Sergipe e pelo período de sua construção dentro da região com o maior número de engenhos desses Estados, acredita-se que os dados corroboram a datação de entrada de pataqueiro no PB indicada por Houaiss (2007), logo pataqueiro seria uma inovação léxica concorrendo diatopicamente com macaqueiro;

iii) o rio São Francisco não só foi imperativo como limite territorial como também parece impedir a expansão de macaqueiro do recôncavo cacaueiro em direção ao Oeste e Norte da Bahia e, mesmo antes de ultrapassar esses limites, essa via fluvial favorece a inovação e/ou

\footnotetext{
${ }^{21}$ Ferreira (1986, p. 1280) acrescenta essa informação circunstancial, que também é corroborada pela disposição dos pontos de pataqueiro.
} 
o uso generalizante de lexias para o tema em questão.

Com exceção de ganhador (de patacas), que poderia ser uma inovação de pataqueiro ou o contrário, as demais lexias, aparentemente, são respostas imprecisas/generalizantes ou eufêmicas para o tema, logo demandam uma reflexão mais detalhada sobre suas motivações e recorrências na fala de alguns informantes.

\section{Referências}

AMATO, C.; NEVES, I. S.; RUSSO, A. Livro das moedas do Brasil: 1643 até o presente. 12 ed. São Paulo: Artgraph Serviços Gráficos, 2008.

AZEVEDO, E. B. Engenhos do recôncavo baiano. Brasília: IPHAN, Programa Monumenta, 2009.

BETHELL, L. O Brasil colonial, c. 1580-1750: as grandes lavouras e as periferias. In: (Org.). História da América Latina: a América Latina colonial. Tradução de Mary Amazonas Leite Barros e Magda Lopes. São Paulo: Edusp, 1999, v. 1-2.

BLUTEAU, R. Vocabulario portuguez e latino: aulico, anatomico, architectonico, bellico, botanico, brasilico, comico, critico, chimico, dogmatico, dialectico, dendrologico, ecclesiastico, etymologico, economico, florifero, forense, fructifero... Portugal: Colégio das Artes da Companhia de Jesus, 1712-1728.

CARDOSO, S. A. M. et al. Atlas linguístico do Brasil. Londrina: Eduel, v. 2, 2014.

CARDOSO, S. A. M. Geolinguística: tradição e modernidade. São Paulo: Parábola, 2010.

CHAMBERS, J. K; TRUDGILL, P. La dialectología. Madrid: Visor Libros, 1994.

FERREIRA, A. B. H. Novo dicionário Aurélio da língua portuguesa. 2 ed. Rio de Janeiro: Nova Fronteira, 1986.

FERREIRA, C.; CARDOSO, S. A. M. A dialetologia no Brasil. São Paulo: Contexto, 1994.

FERREIRA, C.; FREITAS, J.; MOTA, J. A. et al. Atlas lingüístico de Sergipe. Salvador: Universidade Federal da Bahia: Fundação Estadual de Cultura de Sergipe, 1987.

GALLAS, A. O. G.; GALLAS, F. D. As moedas contam a história do Brasil. Trad. Elisabete Hart. São Paulo: Magma, 2007.

HOUAISS, A. Dicionário Houaiss da língua portuguesa. 2 ed. Rio de Janeiro: Objetiva, 2007.

ISQUERDO, A. N.; CARVALHO, P. M. O. Léxico e ambiente rural: um estudo de designações para "trabalhador de enxada em roça alheia" no Centro-Oeste do Brasil. In: MOTA, J. A.; CARDOSO, S. A. M.; PAIM, M. M. T. (Orgs.). Documentos 3: projeto atlas linguístico do Brasil. Salvador: Vento Leste, 2012. MALDONADO, R. Moedas brasileiras: livro oficial. 4. ed. Itália: MBA, 2016. MARROQUIM, M. A língua do Nordeste: Alagoas e Pernambuco. 3. ed. Curitiba: HD Livros, 1996. MOTA, J. A.; CARDOSO, S. A. M. Para uma nova divisão dos estudos dialetais brasileiros. In: (Orgs.).

Documentos 2: projeto atlas linguístico do Brasil. Salvador: Quarteto, 2006.

NASCENTES, A. O linguajar carioca. 2 ed. Rio de Janeiro: Organização Simões, 1953. 
PARANHOS DA SILVA, J. J. O idioma do hodiermo Portugal comparado com o do Brasil. Rio de Janeiro: Typographia Lourenço Winte, 1879-1882.

PASSINI, J.; GAIO, A. P. Esboço de um atlas linguístico de Minas Gerais. Rio de Janeiro: Ministério da Educação e Cultura; Casa de Rui Barbosa; Universidade Federal de Juiz de Fora, 1977.

ROSSI, N. Sôbre designações para trabalhador de enxada na Bahia: carta 23 do atlas prévio dos falares baianos. In: Associação brasileira de antropologia: VI reunião brasileira de antropologia. São Paulo, s. n., 1963.

A dialetologia. ALFA. Marília: UNESP, 1967, vol. 11, p. 89-115. Disponível em: < https://periodicos.fclar.unesp.br/alfa/article/view/3299 >. Acesso em: 20 jan. 2019.

. Atlas prévio dos falares baianos. Salvador: Universidade Federal da Bahia; Instituto Nacional do Livro; Ministério da Educação e Cultura, 1963.

Recebido em 05/10/2019 e aprovado em 22/11/2019. 